\title{
Geographic Flower Trait Variation of Aquilegia buergeriana Sieb. et Zucc. var. buergeriana on Mt. Norikura and the Utsukushigahara Highland, Japan
}

\author{
Mitsuru Hattori ${ }^{* \#}$, Yusuke Nagano ${ }^{1 *}$, Takao Itino ${ }^{1,2}$ \\ ${ }^{1}$ Department of Biology, Faculty of Science, Shinshu University, Matsumoto, Japan \\ ${ }^{2}$ Institute of Mountain Science, Shinshu University, Matsumoto, Japan \\ Email: ${ }^{\text {mtr.hattori@gmail.com }}$
}

Received 26 May 2014; revised 15 July 2014; accepted 4 August 2014

Copyright (C) 2014 by authors and Scientific Research Publishing Inc.

This work is licensed under the Creative Commons Attribution International License (CC BY). http://creativecommons.org/licenses/by/4.0/

cC) (7) Open Access

\begin{abstract}
Many studies have argued the importance of the flower-pollinator size matching for flower trait diversification. However, non-pollinator agents may also influence flower traits. In this study, we investigated the altitudinal variation of flower size (spur length, stamen length, petal blade length, corolla diameter, and sepal length) and flower visitors of Aquilegia buergeriana var. buergeriana (long-spurred columbine) in central Japan. Although this species was primarily visited by Bombus consobrinus, which has an unvarying mouthpart length, flower sizes varied greatly among populations with no correlation with altitude. These results suggest that non-pollinator and non-meteorological agents, directly and/or indirectly, impose selection pressure on flower size in $A$. buergeriana.
\end{abstract}

Keywords

Bumblebee, Flower Visitor Composition, Plant-Pollinator Interaction, Ranunculaceae

\section{Introduction}

Geographic flower trait variation (e.g., corolla tube length, spur length) often correlates with geographic variation in the composition of the pollinator assemblage [1]-[4] (for reviews see [5] [6]). For example, Gómez et al.

*The authors contributed equally to the paper.
${ }^{*}$ Corresponding author.

How to cite this paper: Hattori, M., Nagano, Y. and Itino, T. (2014) Geographic Flower Trait Variation of Aquilegia buergeriana Sieb. et Zucc. var. buergeriana on Mt. Norikura and the Utsukushigahara Highland, Japan. American Journal of Plant Sciences, 5, 2686-2692. http://dx.doi.org/10.4236/ajps.2014.518283 
[2] [3] found that variation of flower morphology in Erysimum mediohispanicum is affected by geographical variation in the composition of the pollinator assemblage. On the other hand, variation of flower morphology can also be affected by geographical variation of non-pollinator agents (for a review see [7]). Lambrecht and Dawson [8] showed that flower size varied along a gradient of soil moisture availability in multiple plant species. Furthermore, large variation of flower morphology occasionally leads to speciation [1] (for a review see [9]). Therefore, a deeper knowledge of the factors that can cause geographic variation of flower morphology is important for understanding plant diversification and the evolution of floral traits. In this study, we observed geographic variation of floral size in the long-spurred columbine Aquilegia buergeriana Sieb. et Zucc. var. buergeriana (Ranunculaceae). Our purpose was to examine the relative importance of pollinator and non-pollinator selection agents in determining variation of floral traits.

In Japan, genus Aquilegia comprises only A. buergeriana var. buergeriana and A. flabellata var. pumila. Aquilegia flabellata is distributed only in the alpine zone of central Japan. In contrast, A. buergeriana is distributed across a wide altitudinal range, from the subalpine to the montane zones [10]. The long-spurred flowers of Aquilegia buergeriana are pollinated by bumblebees [11]. In North American Aquilegia, Whittall and Hodges [12] showed that floral traits such as spur length are selected by pollinators, and variation of floral traits reflects variation in the composition of the pollinator assemblage. In the mountainous regions of central Japan, the distributions of different bumblebee species change along altitude [13]. Thus, we can predict that the bumblebee species that pollinate A. buergeriana vary along altitude, and, thus, that flower size in A. buergeriana, as with other Aquilegia species, might correlate with variation of the pollinating bumblebee species [12].

In this paper, we describe altitudinal variations of flower size and flower visitors of A. buergeriana in several populations on Mt. Norikura and the Utsukushigahara Highland, and discuss the relative importance of abiotic and biotic (i.e., pollinator) factors in determining flower size variation along altitude.

\section{Materials and Methods}

\subsection{Plant Species}

Aquilegia buergeriana Sieb. et Zucc. var. buergeriana (Ranunculaceae) is a protandrous, perennial herb with long-spurred flowers pollinated primarily by Bombus diversus [10] [11] (Figure 1). Flowers of A. buergeriana vary in color; in particular, the spurs and the petal blades vary in color from light yellow to red-brown.

\subsection{Study Area}

We studied altitudinal changes in flower size and visiting bumblebee species in six populations of $A$. buergeriana in two mountain regions of central Japan (Table 1, Figure 2). The study was conducted during the peak flowering season of each population in July 2013.

\subsection{Variations in Visiting Bumblebee Species}

We observed the bumblebee species visiting each population of A. buergeriana. We conducted observations in

Table 1. The six studied populations of A. buergeriana var. buergeriana.

\begin{tabular}{ccccccc}
\hline Population & Altitude $(\mathrm{m})$ & Latitude $\left({ }^{\circ} \mathrm{N}\right)$ & Longitude $\left({ }^{\circ} \mathrm{E}\right)$ & $\begin{array}{c}\text { No. of plants } \\
\text { No. of measured } \\
\text { flowers }\end{array}$ & $\begin{array}{c}\text { Visitors observed } \\
\text { (number) }\end{array}$ \\
\hline $\begin{array}{c}\text { Mt. Norikura } \\
\text { Ichinose }\end{array}$ & 1488 & 36.1173 & 137.6284 & $<30$ & 15 & - \\
Shirahone 1 & 1596 & 36.1423 & 137.6284 & $<15$ & 9 & $B C(6), B D(1), B H(1)$ \\
Shirahone 2 & 1620 & 36.1469 & 137.6303 & $<15$ & 10 & $B C(5)$ \\
Norikura & 1721 & 36.1096 & 137.6071 & $<30$ & 20 & $B C(1)$ \\
Utsukushigahara & & & & & & \\
Highland & & & & & 14 & $B C(3)$ \\
Hakamagoshi & 1612 & 36.2465 & 138.0570 & $<30$ & 15 & $B C(1)$ \\
Omoideno-oka & 1901 & 36.2523 & 138.0786 & $<30$ & & \\
\hline
\end{tabular}

*Observed in each population during an observation period of at least 1 h. BC, Bombus consobrinus; $B D$, B. diversus; BH, B. honshuensis; -, species not identified. 

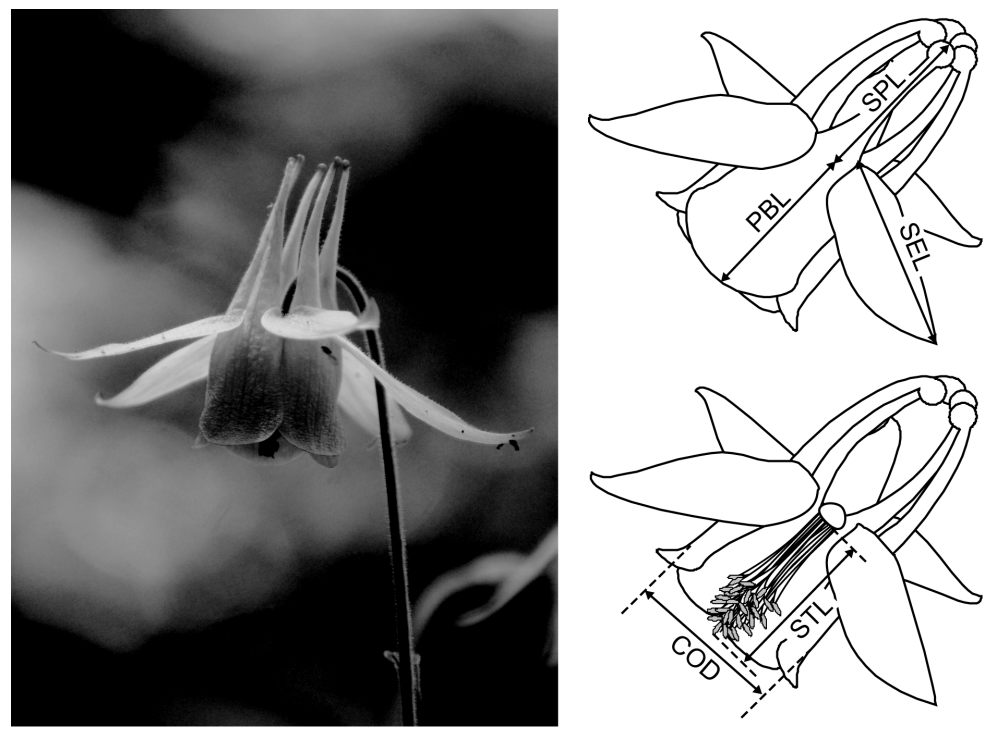

Figure 1. An A. buergeriana var. buergeriana flower. The diagrams show the measured flower traits: SPL, spur length; STL, stamen length; PBL, petal blade length; COD, corolla diameter; SEL, sepal length.

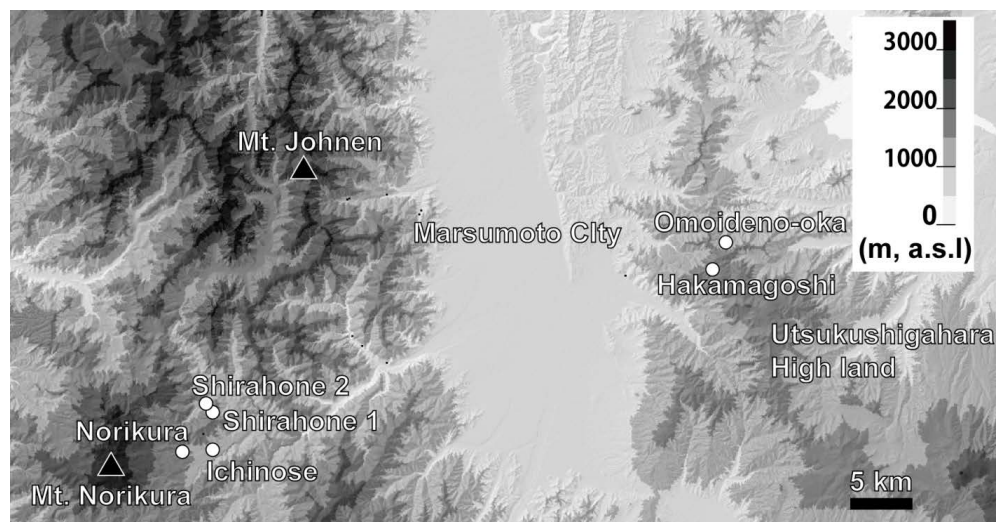

Figure 2. Locality of A. buergeriana var. buergeriana populations. See Table 1 for details.

each of the six populations for at least 1 hour between 08:00 and 15:00 JST during the peak flowering season. During each observation period, we counted the number of individuals of each bumblebee species visiting the population. We identified bumblebee species based on their characteristic traits (i.e., body size, body color) [14].

\subsection{Flower Size Variation}

From each population, we haphazardly picked out 9 - 20 individual plants and haphazardly selected one flower on each plant for morphological measurement. We measured five different flower dimensions, spur length (SPL), stamen length (STL), petal blade length (PBL), corolla diameter (COD), and sepal length (SEL) (Figure 1) of each flower with a digital caliper $(0.01 \mathrm{~mm}$ precision). When bumblebees visit A. buergeriana flowers, they cling to the stamens and insert their mouthpart into the spur to gather nectar. Therefore, SPL and STL may determine pollination efficiency, because their size relative to the pollinator's mouthpart length and body size may affect the efficiency of pollen transfer to the bees [12]. PBL and COD may determine the behavior of the pollinating bumblebees because these traits may limit the size of the pollinator that can alight on the flower and crawl into the corolla. On the other hand, SEL may not influence pollination because it probably does not affect either pollination efficiency or bumblebee behavior. 


\subsection{Statistical Analysis}

We explored the differences in the five flower dimensions among populations by using one-way analysis of variance (ANOVA) followed by pair wise comparisons with Tukey's HSD post-hoc test. We also calculated Pearson's correlations among the five flower traits. In a series of multiple tests, significance levels were adjusted using the sequential Bonferroni correction [15]. The statistical analyses were performed with the JMP version 9.0 software package (SAS Inc., Cary, NC).

\section{Results}

In the study areas, Aquilegia buergeriana was visited primarily by Bombus consobrinus (Table 1). However, the Shirahone 1 population of $A$. buergeriana was visited not only by B. consobrinus but also by $B$. diversus and $B$. honshuensis (Table 1). Although we found significant variations in the five flower dimensions (SPL, STL, PBL, COD, SEL) among populations, SPL and STL variations were smaller than those of other traits (SPL: $F=3.95$, $P=0.003$; STL: $F=5.50, P<0.001$; PBL: $F=21.31, P<0.001$; COD: $F=14.21, P<0.001$; SEL: $F=14.50$, $P<0.001$; Figure 3).
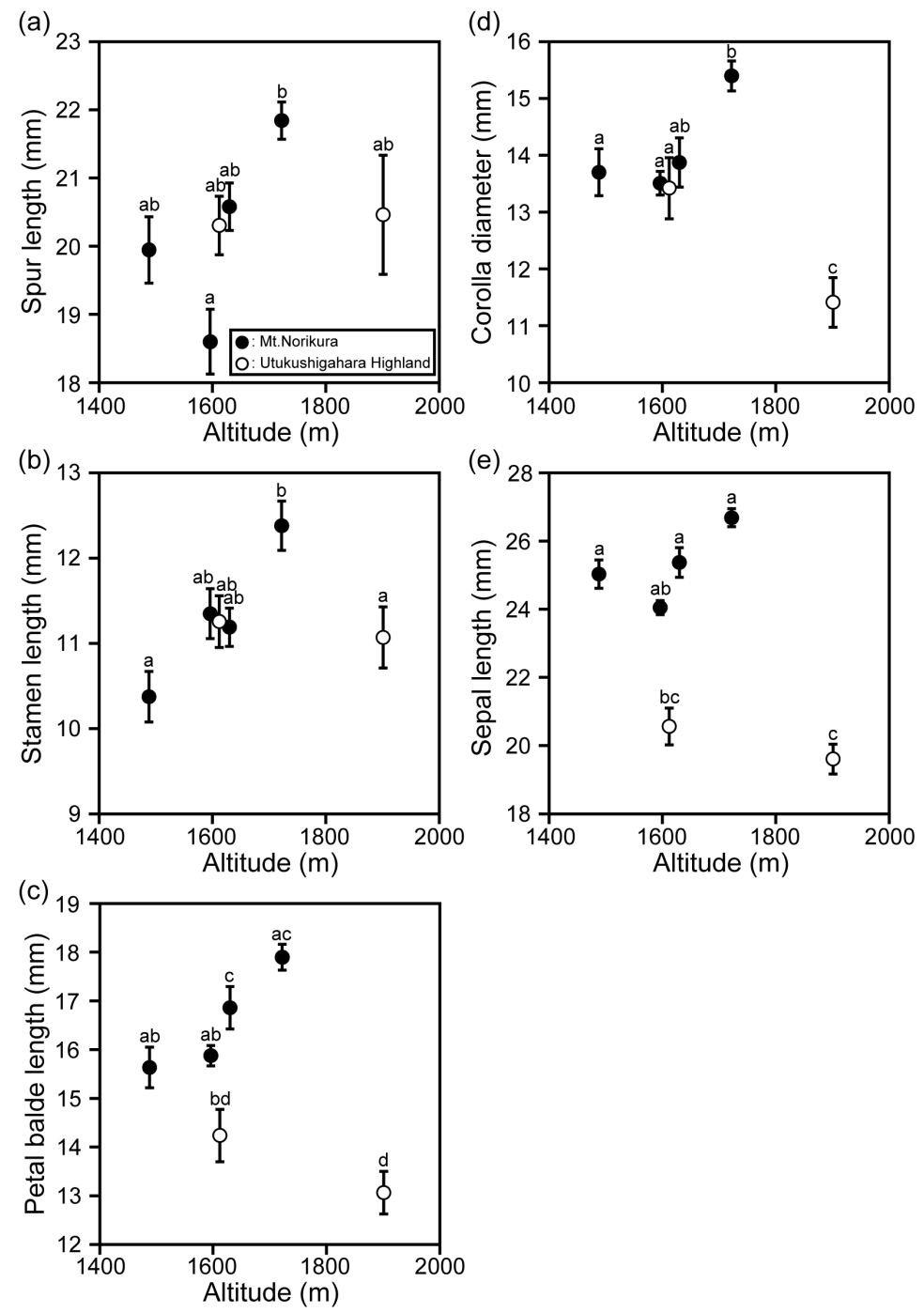

Figure 3. Geographic variation (mean \pm SE) of five floral traits (SPL, STL, PBL, COD, and SEL; see Figure 1). Each circle represents one population (black, populations on Mt. Norikura; white, population on the Utsukushigahara Highland). Different lowercase letters indicate significant differences between the populations $(P<0.05$; Tukey’s HSD post hoc pair wise comparisons). 
The measured traits showed significant positive correlations with each other except for SPL $\times$ PBL and SPL $\times$ COD (Figure 4). In particular, PBL $\times$ COD and PBL $\times$ SEL showed strong positive correlations (PBL $\times$ COD: $r$ $=0.63, P<0.001$; PBL $\times$ SEL: $r=0.69, P<0.001)$.

\section{Discussion}

Many studies have argued the importance of the flower-pollinator size match for flower trait diversification [2] [3] [16] [17]. However, Strauss and Whittall [7] argued that the impact of pollinators on flower shape is frequently over blown; moreover, they reported that in numerous species non-pollinator agents influenced flower traits such as petal color and flower size. In this study, we investigated the altitudinal variation of flower dimensions and flower visitors of $A$. buergeriana. Although the studied populations of A. buergeriana were primarily visited by $B$. consobrinus, the five measured flower dimensions varied among populations and did not correlate with altitude (Figure 3). These results suggest that non-pollinator and non-meteorological agents directly or indirectly select for flower size in A. buergeriana.

Although the measured flower traits did not vary along altitude, some traits were correlated with respect to size (Figure 4). This result suggests that trait size may be affected by population-specific non-pollinator agents (e.g., soil nutrient availability, light condition, presence of herbivores, density of plant individuals). Many studies have shown that non-pollinator agents can affect flower size and shape [8] [18] [19] (for a review see [7]). For example, flower size in Rosmarinus officinalis correlates not only with pollinator size but also with soil moisture and nutrient content [20].

Selection pressures exerted by non-pollinator agents frequently conflict with those exerted by pollinators [7]. It is possible that such a conflict also occurs in A. buergeriana and affects trait variation. In particular, SPL, which showed small geographic variation, did not correlate with PBL or COD (Figure 3 and Figure 4). This result suggests that at least SPL is selected for not only by non-pollinator agents but also by pollinators. Adaptive radiation of Aquilegia spur length according to the pollinator fauna has been reported at the species level [12]. In this study, A. buergeriana was visited by B. consobrinus, B. diversus, and B. honshuensis (Table 1). Among these bumblebees, $B$. consobrinus has the longest mouthpart [21] (proboscis length: $B C$, about 18mm; $B D$, about $13 \mathrm{~mm} ; B H$, about $10 \mathrm{~mm}$ ). In populations visited only by $B$. consobrinus (Shirahone 2, Norikura, Hakamagoshi, and Omoideno-oka), SPL was longer than in the population (Shirahone 1) visited by multiple bumblebee species (Table 1, Figure 2).

\section{Conclusion}

Our results suggest that non-pollinator and non-meteorological agents, directly and/or indirectly, impose selec-

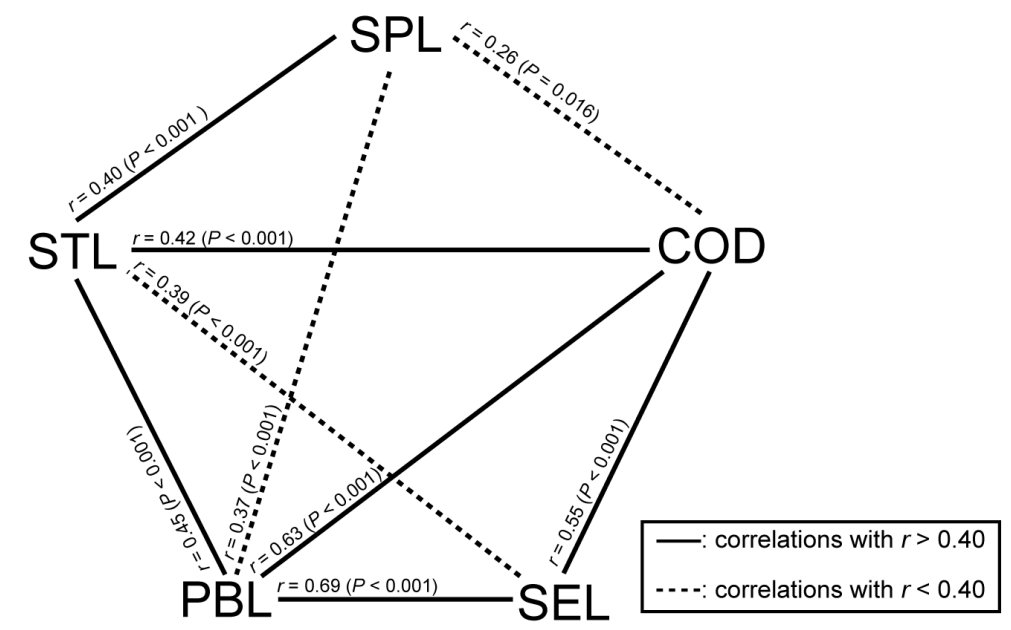

Figure 4. Pearson's correlation coefficients $(r)$ between flower dimensions of A. buergeriana. Solid lines show correlations with $r>0.40$ and dashed lines show correlations with $r<0.40$. A pair of traits that is not connected did not show significant correlation. 
tion pressure on flower size in A. buergeriana with long-spurred flowers pollinated primarily by B. consobrinus. This study proposes viewpoints that not only pollinators but also other factors affect flower-size evolution even in plants that have clearly specialized flower traits. Further study is needed to ascertain precisely the extent to which pollinator and non-pollinator agents affect flower morphology in A. buergeriana.

\section{Acknowledgements}

We thank Shin Egawa for help with the field survey. This study was supported by the Global Environmental Research Fund (D-0904) of the Ministry of the Environment, Japan, and by the Japanese Alps Inter-University Cooperative Project, Ministry of Education, Culture, Sports, Science and Technology (MEXT), Japan. We thank Chushin District Forest Office (Forestry Agency) and Matsumoto Regional Office (Nagano Prefectural government) for permission to work in the study areas.

\section{References}

[1] Schemske, D.W. and Bradshaw, H.D. (1999) Pollinator Preference and the Evolution of Floral Traits in Monkeyflowers (Mimulus). Proceedings of the National Academy of Sciences of the United States of America, 96, 11910-11915. http://www.pnas.org/content/96/21/11910 http://dx.doi.org/10.1073/pnas.96.21.11910

[2] Gómez, J.M., Perfectti, F., Bosch, J. and Camasho, J.P.M. (2009) A Geographic Selection Mosaic in a Generalized Plant-Pollinator-Herbivore System. Ecological Monographs, 79, 245-263.

http://www.esajournals.org/doi/abs/10.1890/08-0511.1 http://dx.doi.org/10.1890/08-0511.1

[3] Gómez, J.M., Abdelaziz, M., Camacho, J.P.M., Muñoz-Pajares, A.J. and Perfectti, F. (2009) Local Adaptation and Maladaptation to Pollinators in a Generalist Geographic Mosaic. Ecology Latters, 12, 672-682. http://onlinelibrary.wiley.com/doi/10.1111/j.1461-0248.2009.01324.x/full

[4] Sun, M., Gross, K. and Schiestle, F.P. (2014) Floral Adaptation to Local Pollinator Guilds in a Terrestrial Orchid. Annals of Botany, 113, 289-300. http://aob.oxfordjournals.org/content/113/2/289.short http://dx.doi.org/10.1093/aob/mct219

[5] Herrera, C.M., Castellanos, M.C. and Mónica, M. (2006) Geographic Context of Floral Evolution: Towards an Improved Research Programmein Floral Diversification. In: Harder, L.D. and Barrett, S.C.H., Eds., Ecology and Evolution of Flowers, Oxford University Press, Oxford, 278-294.

[6] Mitchell, R.J., Irwin, R.E., Flanagan, R.J. and Karron, J.D. (2009) Ecology and Evolution of Plant-Pollinator Interactions. Annals of Botany, 109, 1355-1363. http://aob.oxfordjournals.org/content/103/9/1355.short http://dx.doi.org/10.1093/aob/mcp122

[7] Strauss, S.Y. and Whittall, J.B. (2006) Non-Pollinator Agents of Selection on Floral Traits. In: Harder, L.D. and Barrett, S.C.H., Eds., Ecology and Evolution of Flowers, Oxford University Press, Oxford, 120-138.

[8] Lambrecht, S.C. and Dawson, T.E. (2007) Correlated Variation of Floral and Leaf Traits along a Moisture Availability Gradient. Oecologia, 151, 574-583. http://link.springer.com/article/10.1007/s00442-006-0617-7 http://dx.doi.org/10.1007/s00442-006-0617-7

[9] Van der Niet, T., Peakall, R. and Johnson, S.D. (2014) Pollinator-Driven Ecological Speciation in Plants: New Evidence and Future Perspective. Annals of Botany, 113, 199-211. http://aob.oxfordjournals.org/content/113/2/199.short http://dx.doi.org/10.1093/aob/mct290

[10] Tamura, M. and Shimizu, T. (1999) Ranunculaceae. In: Satake, Y., Ohwi, J., Kitamura, S., Watari, S. and Tominari, T., Eds., Wild Flowers of Japan: Herbaceous Plants (Including Dwarf Subshrubs), Heibonsha, Tokyo, 82.

[11] Itagaki, T. and Sakai, S. (2006) Relationship between Floral Longevity and Sex Allocation among Flowers within Inflorescences in Aquilegia buergeriana var. oxysepala (Ranunculaceae). American Journal of Botany, 93, 1320-1327. http://www.amjbot.org/content/93/9/1320.short http://dx.doi.org/10.3732/ajb.93.9.1320

[12] Whittall, J.B. and Hodges, S.A. (2007) Pollinator Shifts Drive Increasingly Long Nectar Spurs in Columbine Flowers. Nature, 447, 706-709. http://www.nature.com/nature/journal/v447/n7145/abs/nature05857.html http://dx.doi.org/10.1038/nature05857

[13] Tomono, T. and Sota, T. (1997) The Life History and Pollination Ecology of Bumblebee in the Alpine Zone of Central Japan. Japanese Journal of Entomology, 65, 237-255.

[14] Takamizawa, K. (2005) Bombini. In: Takamizawa, K., Ed., The Japanese Social Wasps and Bees, The Shinano Mai- 
nichi Shimbun, Nagano, 177-248.

[15] Rice, W.R. (1989) Analyzing Tables of Statistical Tests. Evolution, 43, 223-225. http://www.jstor.org/stable/2409177 http://dx.doi.org/10.2307/2409177

[16] Herrera, C.M., Castellanos, M.C. and Mónica, M. (2006) Geographic Context of Floral Evolution: Towards an Improved Research Programmein Floral Diversification. In: Harder, L.D. and Barrett, S.C.H., Eds., Ecology and Evolution of Flowers, Oxford University Press, Oxford, 278-294.

[17] Gómez, J.M., Muñoz-Pajares, A.J., Abdelaziz, A.Z., Lorite, J. and Perfectti, F. (2014) Evolution of Pollination Niches and Floral Divergence in the Generalist Plant Erysimum mediohispanicum. Annals of Botany, 113, 237-249. http://aob.oxfordjournals.org/content/113/2/237.short

[18] Galen, C. and Butchart, B. (2003) Ants in Your Plants: Effects of Nectar-Thieves on Pollen Fertility and Seed-Siring Capacity in the Alpine Wildflower, Polemonium viscosum. Oikos, 101, 521-528. http://onlinelibrary.wiley.com/doi/10.1034/j.1600-0706.2003.12144.x/full

[19] Cariveau, D., Irwin, R.E., Brody, A.K., Gracia-Mayeya, L.S. and Von Der Ohe, A. (2004) Direct and Indirect Effects of Pollinators and Seed Predators to Selection on Plant and Floral Traits. Oikos, 104, 15-26. http://onlinelibrary.wiley.com/doi/10.1111/j.0030-1299.2004.12641.x/full http://dx.doi.org/10.1111/j.0030-1299.2004.12641.x

[20] Hererra, J. (2005) Flower Size Variation in Rosmarinus officinalis: Individuals, Population and Habitats. Annals of Botany, 95, 431-437. http://aob.oxfordjournals.org/content/95/3/431.short http://dx.doi.org/10.1093/aob/mci041

[21] Suzuki, K., Dohzono, I., Hiei, K. and Fukuda, Y. (2002) Pollination Effectiveness of Three Bumblebee Species on Flowers of Hosta sieboldiana (Liliaceae) and Its Relation to Floral Structure and Pollinator Sizes. Plant Species Biology, 17, 139-146. http://onlinelibrary.wiley.com/doi/10.1046/j.1442-1984.2002.00076.x/full http://dx.doi.org/10.1046/j.1442-1984.2002.00076.x

\section{List of Abbreviations}

SPL: Spur length

STL: Stamen length

PBL: Petal balde length

COD: Corolla diameter

SEL: Sepal length

BC: Bombus consobrinus

$\mathrm{BD}$ : Bombus diversus

$\mathrm{BH}$ : Bombus honshuensis 
Scientific Research Publishing (SCIRP) is one of the largest Open Access journal publishers. It is currently publishing more than 200 open access, online, peer-reviewed journals covering a wide range of academic disciplines. SCIRP serves the worldwide academic communities and contributes to the progress and application of science with its publication.

Other selected journals from SCIRP are listed as below. Submit your manuscript to us via either submit@scirp.org or Online Submission Portal.
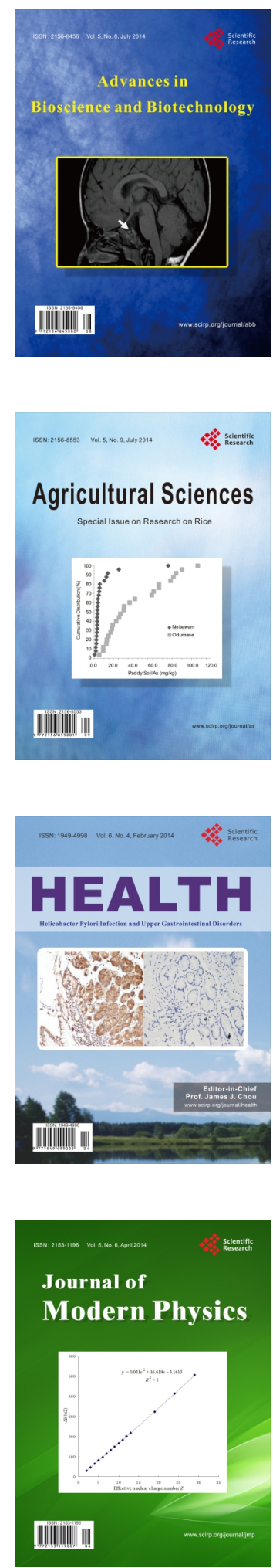
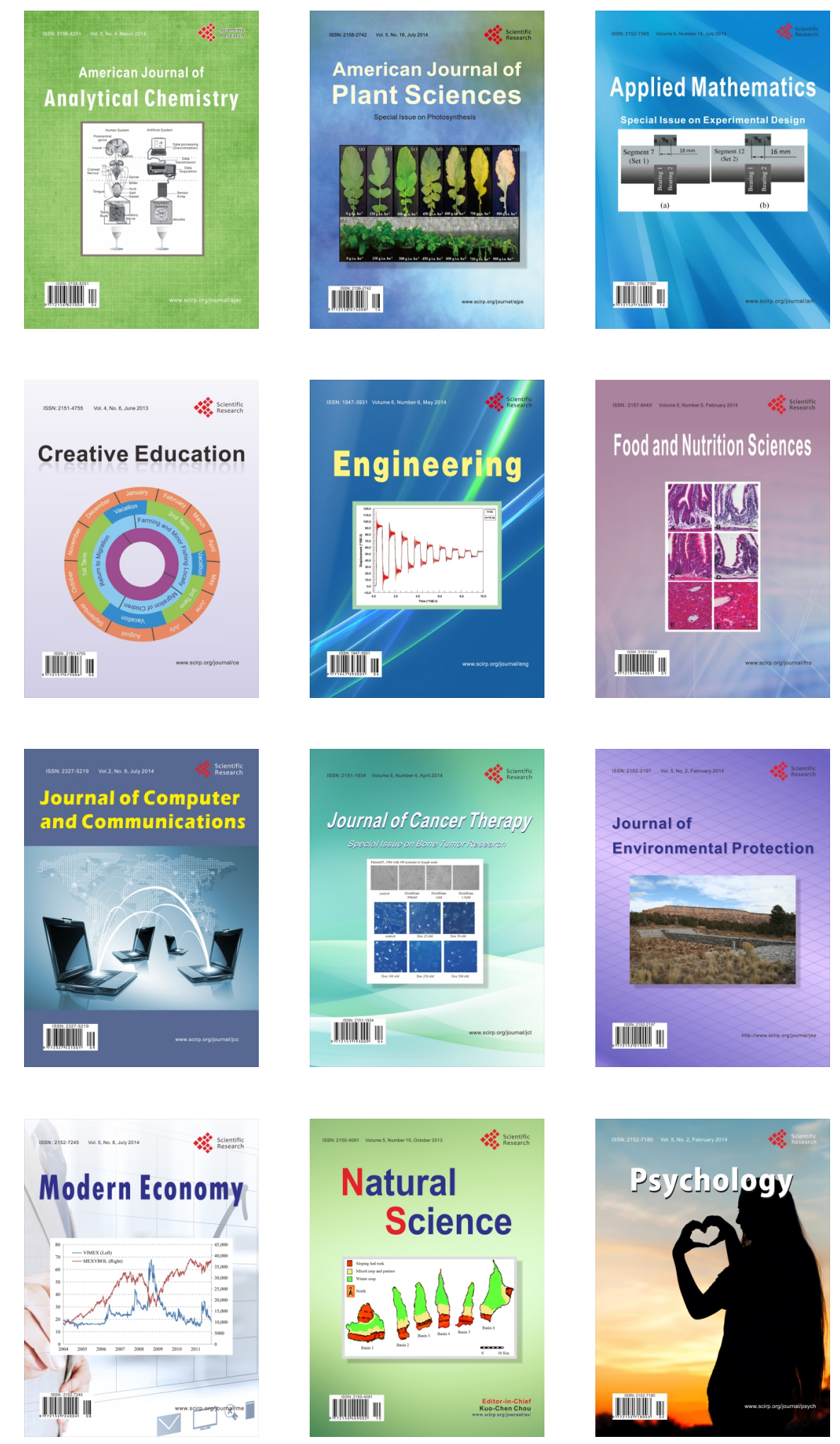